\title{
Cardiac diseases in pregnancy and its feto-maternal outcome
}

\author{
Parul T. Shah, Mohini A. Bhagat*, Rina V. Patel, Swati M. Yadav
}

Department of Obstetrics and Gynecology, VS Hospital, Ahmedabad, Gujarat, India

Received: 14 September 2018

Accepted: 11 October 2018

\section{*Correspondence:}

Dr. Mohini A. Bhagat,

E-mail: mohini.bhagat2111@gmail.com

Copyright: (c) the author(s), publisher and licensee Medip Academy. This is an open-access article distributed under the terms of the Creative Commons Attribution Non-Commercial License, which permits unrestricted non-commercial use, distribution, and reproduction in any medium, provided the original work is properly cited.

\section{ABSTRACT}

Background: Cardiac disease complicates 1-3\% of all pregnancies. Of this Rheumatic heart disease constitute $74 \%$ and congenital heart disease $26 \%$.

Methods: A retrospective study of all patients with cardiac diseases delivered was conducted. A tabulated representation of the data was done. The various cardiac diseases were categorized according the severity, NYHA classification, type of pathology, the maternal and perinatal outcome was assessed, and the maternal mortality and perinatal mortality was recorded.

Results: $84 \%$ patients belonged to age group 20-29 years. $8 \%$ were teen aged and $4 \%$ patients were elderly. $64 \%$ patients were either $\mathrm{P} 0+0$ or $\mathrm{P} 0+1.8 \%$ patients were $\mathrm{P} 0+3$ and $2 \%$ patient were $\mathrm{P} 3+0.74 \%$ patients had RHD. $26 \%$ had grade I, $40 \%$ had grade II, $20 \%$ patients had grade III and $14 \%$ had grade IV heart disease. The associated complications were anemia $46 \%$, Respiratory tract infection $12 \%$, pregnancy induced hypertension $2 \%$ and recurrent rheumatic fever $2 \% .48 \%$ had normal vaginal delivery, $20 \%$ had forceps delivery and $32 \%$ had caesarean delivery. One mother died of heart failure. All patients of grade I (100\%) had term delivery. $23.07 \%$ of grade I, $30 \%$ of grade II, $60 \%$ of grade III and $100 \%$ babies of grade IV mothers were of low birth weight $(<2.5 \mathrm{~kg})$. Babies weighing $<1.5$ $\mathrm{kg}$ were seen in $5 \%$ grade II, $10 \%$ grade III and $42.85 \%$ mothers with grade IV disease. 2 of grade IV and each of grade I, II and III died.

Conclusions: Feto-maternal outcome can be improved with close supervision of obstetrician and cardiologist throughout the pregnancy by antenatal care, early diagnosis and management.

Keywords: Cardiac disease, NYHA classification, Outcome, Pregnancy, RHD

\section{INTRODUCTION}

Cardiac disease during pregnancy is still a major problem worldwide as there are challenges faced in feto-maternal outcome and its management. Heart disease in pregnancy is of great clinical significance both to the cardiologist and obstetrician. Cardiovascular disease complicates around $1-3 \%$ of all pregnancy and is responsible for 10 $15 \%$ of maternal death and is the leading cause of maternal death internationally. ${ }^{1-4}$ Since more women with congenital or acquired heart disease are reaching child bearing age due to improved medical and surgical care, the incidence of cardiovascular disease in pregnancy is increasing. There is marked hemodynamic changes during pregnancy. The pregnant women are in a hyperdynamic and volume-overloaded state as a result of physiological changes. These changes result in increased demand on the cardiovascular system. In normal women the cardiac reserve is sufficient to accommodate this increased work load. However, women with underlying heart disease cannot tolerate these additional hemodynamic burdens of pregnancy. So, there may be significant risk to the mother, fetus or both. Therefore, pregnancy may exaggerate underlying disease, resulting in increased morbidity and mortality. Despite advancement in medical care, heart disease in pregnancy is associated with high maternal and perinatal morbidity and mortality particularly in developing countries. ${ }^{5}$ This 
study was done to enlighten the total incidence of pregnancy with heart disease and its effects on pregnancy outcomes in term of maternal and perinatal morbidity and mortality.

\section{METHODS}

\section{Study setting}

Department of Obstetrics and Gynecology, V.S Hospital, Smt. N.H.L Medical College, Ahmedabad, Gujarat

\section{Definition of problem}

In the developing country like India along with hemodynamic changes, the presence of complicating factor like anemia, under reporting disease, inadequate antenatal care and poor socio-economic condition add to the high maternal death to the cardiac disease in pregnancy.

\section{Inclusion criteria}

- Women with diagnosed heart disease with pregnancy admitted through Out-Patient-Department (OPD) and Emergency in our department of Obstetrics and Gynecology.

\section{Exclusion criteria}

- Mother with coronary cardiac disease

- Mothers with medical disorder other than cardiac disease.

\section{Sample size}

All reported diagnosed case of cardiac disease with pregnancy fulfilling inclusion and exclusion criteria admitted through OPD and Emergency of Obstetrics and Gynecology during the study period.

\section{Method of data collection}

Data were collected from ward, labor room, OT record sheet, neonatal units. Predesigned record sheet was filled up.

\section{Study design}

- Observational Study

\section{Study tool}

\section{Detailed History}

- Age

- Parity

- Gestational Age

- Socio-economic Status

- Obstetrics history
- Past history of any cardiological event

\section{Clinical examination}

- Obstetrics Examination

- Cardiovascular and Respiratory System Examination

\section{Investigations}

- $\mathrm{Hb} \%$, Blood grouping and $\mathrm{RH}$ typing, fasting blood sugar, FT4, TSH, Thalessemia screening, HIV screening, HBSAg, HCV

- $\mathrm{ECG}$

- Echocardiography

- Chest X Ray with abdominal shield (*only where applicable)

- USG for feto-placental profile and amniotic fluid index

50 cases were studied in this observational study. Ethical permission was taken. The patients fulfilled the inclusion criteria were selected and recruited for the study. Written informed consent was taken for participation in the study. Previous medical history relevant to heart disease such as past history of rheumatic fever, consultation and advise with cardiologist, taking associated medication or any previous history of heart failure were also evaluated.

Past surgical history especially cardiac operation was taken with special reference to type of operation, type of lesion and clinical improvement. The entire study population were evaluated by New York Heart Association functional grading. All cases were referred to the cardiologist after admission and managed by joint supervision of the obstetrician and cardiologist throughout the pregnancy and puerperium. A careful supervision was made on each labor case and mode of delivery was evaluated. The patients were kept in hospital after delivery for any complications including heart failure. Status of baby was evaluated at the time of delivery and during hospital stay. All the patients after discharge were advised to come OPD for follow up 6 weeks after delivery, and to consult cardiologist.

\section{RESULTS}

In this present series there were 50 confirmed cases of heart disease out of 2500 deliveries giving an incidence of $2 \%$.

Table 1: Age distribution ( $\mathrm{N}=50)$.

\begin{tabular}{|lll|}
\hline Age in years & No of patients & Percentage \\
\hline$<20$ & 4 & 8 \\
\hline $20-24$ & 17 & 34 \\
\hline $25-29$ & 25 & 50 \\
\hline $30-34$ & 2 & 4 \\
\hline$>35$ & 2 & 4 \\
\hline
\end{tabular}


Table 1 represented majority (84\%) patients were within twenties. $8 \%$ patients were still in their teen age. $4 \%$ patients had pregnancy after 35 . This reflected the Indian trend of early marriage and pregnancy.

Table 2: Parity distribution $(\mathrm{N}=50)$.

\begin{tabular}{|lll|}
\hline Parity & No of patients & Percentage \\
\hline $\mathrm{P} 0+0$ & 27 & 54 \\
\hline $\mathrm{P} 1+0$ & 6 & 12 \\
\hline $\mathrm{P} 0+1$ & 5 & 10 \\
\hline $\mathrm{P} 2+0$ & 1 & 2 \\
\hline $\mathrm{P} 0+2$ & 4 & 8 \\
\hline $\mathrm{P} 2+1$ & 2 & 4 \\
\hline $\mathrm{P} 3+0$ & 1 & 2 \\
\hline $\mathrm{P} 0+3$ & 4 & 8 \\
\hline
\end{tabular}

$64 \%$ of patients in this study were either $\mathrm{P} 0+0$ or $\mathrm{P} 0+1$. Most patients were not aware of their heart ailment till advanced pregnancy. As frequent pregnancy is discouraged, only one patient with $\mathrm{P} 3+0$ was pregnant once again. Among 4 patients with $\mathrm{P} 0+3$ one was known heart case and on treatment and the rest were not aware of their pathology till running pregnancy.

Table 3: Socioeconomic status $(\mathbf{N}=\mathbf{5 0})$.

\begin{tabular}{|lll|}
\hline Economic status & No of patients & Percentage \\
\hline Upper middle class & 2 & 4 \\
\hline Lower middle class & 10 & 20 \\
\hline Lower class & 18 & 36 \\
\hline Below poverty line & 20 & 40 \\
\hline
\end{tabular}

Table 3 described socioeconomic status. $76 \%$ of the patients belonged to either lower income group (LIG) and Below Poverty line (BPL). Majority had rheumatic heart disease which was following rheumatic fever whose incidence is more common among overcrowding LIG. Only $4 \%$ were from upper middle-class family.

Table 4: Rural/urban distribution $(\mathrm{N}=50)$.

\begin{tabular}{|lll|}
\hline Area & No of patients & Percentage \\
\hline Rural & 43 & 86 \\
\hline Urban & 7 & 14 \\
\hline
\end{tabular}

Inspite of having money they were refused by the wellequipped corporate hospital due to severity and associated risk. None of the patient attended were in upper- or middle-class group. $86 \%$ came from rural area and the remaining $14 \%$ were from urban slum area. From table 5 we came to know $74 \%$ patients had rheumatic heart disease which highlighted that the heart disease of rheumatic origin is still rampant in our country. Some had single lesion, some had mixed lesions. $34 \%$ patients $(28 \%$ with RHD and 6\% with CHD) had pulmonary hypertension. $4 \%$ of them had moderate PAH and rest of them had mild PAH. According to New York Heart Association grading system $26 \%$ had class I heart disease while $40 \%$ suffered from class II heart disease. $20 \%$ patients presented with grade III and $14 \%$ of them had grade IV disease at the time of admission. The unbooked cases had come late with either grade III or grade IV disease. $8 \%$ patients were admitted with heart failure. Other complications were atrial fibrillation (AF) (4\%), pulmonary edema $(8 \%)$ and supraventricular tachycardia (2\%). Most of them had mixed symptoms like dyspnea, palpitation, cough etc. though some of them presented with only dyspea.

Table 5: Types of heart disease.

\begin{tabular}{|lll|}
\hline $\begin{array}{l}\text { Type of heart disease } \\
\text { Rheumatic heart disease } \\
\text { (RHD) }\end{array}$ & 37 & 74 \\
\hline MS & 10 & 20 \\
\hline MR & 3 & 6 \\
\hline MS+MR & 7 & 14 \\
\hline AS & 1 & 2 \\
\hline AR & 1 & 2 \\
\hline TR & 1 & 2 \\
\hline MS+PAH & 5 & 10 \\
\hline MS+MR+PAH & 6 & 12 \\
\hline MR+AR+PAH & 2 & 4 \\
\hline MS+MR+AS+PAH & 1 & 2 \\
\hline Congenital heart disease & 13 & 26 \\
\hline ASD with PAH & 2 & 4 \\
\hline ASD without PAH & 7 & 14 \\
\hline VSD with PAH & 1 & 2 \\
\hline VSD without PAH & 1 & 2 \\
\hline PDA & 1 & 2 \\
\hline $\begin{array}{l}\text { Fallot's tetralogy } \\
\text { (corrected) }\end{array}$ & 1 & 2 \\
\hline
\end{tabular}

One patient was admitted after syncopal attack. The common presenting signs were pallor (46\%), tachycardia $(30 \%)$ and edema $(22 \%)$. Other signs were raised JVP (10\%), pulmonary basal crepitation (12\%), hypertension (4\%). One mother died due to congestive heart failure. The associated complications were $46 \%$ moderate to severe anemia, $60 \%$ patients had any of the following complications $12 \%$ Respiratory tract infection, $2 \%$ pregnancy induced hypertension (PIH) and 2\% recurrence of rheumatic fever.

\section{Table 6 Mode of delivery.}

\begin{tabular}{|lll|}
\hline $\begin{array}{l}\text { Mode of delivery } \\
\text { Spontaneous vaginal } \\
\text { delivery }\end{array}$ & 24 & 48 \\
\hline Forceps & 10 & 20 \\
\hline LSCS & & \\
\hline Emergency & 11 & 22 \\
\hline Elective & 5 & 10 \\
\hline
\end{tabular}

Table 6 described that the preferable mode of delivery was spontaneous vaginal delivery $(48 \%)$, forceps were applied to cut short second stage of delivery in $10(20 \%)$ 
patients. Lower uterine Segment Caesarean Section (LSCS) was done in 16 (32\%) mothers, of which 11 were emergency and 5 cases were elective. Emergency LSCS were done for fetal indications but elective LSCS were mainly done for maternal lindication. Indications of emergency LSCS were short induction, post-cesarean pregnancy, fetal distress and maternal distress $2(12.5 \%)$ in each cases and non-progress of labor in $3(18.75 \%)$ cases. Elective LSCS done for the patients who had moderate $\mathrm{PAH}, \mathrm{AF}$ and $\mathrm{PIH}$ for better peripartum management. All case of LSCS were done under epidural anesthesia.

One mother was died due to uncompensated heart failure. The patient had 3 antenatal check-up and one cardiological check-up. She had grade IV disease with $\mathrm{MS}+\mathrm{MR}+\mathrm{AS}+\mathrm{PAH}$. She was offered MTP which she refused as she became pregnant 6 years after marriage. She was advised to be kept admitted throughout pregnancy which too was refused by patient party.
Table 7: Maturity of baby at birth.

\begin{tabular}{|c|c|c|c|}
\hline $\begin{array}{l}\text { Functional } \\
\text { class (NYHA) }\end{array}$ & $\begin{array}{l}<34 \\
\text { weeks }\end{array}$ & $\begin{array}{l}\text { 34-37 } \\
\text { weeks }\end{array}$ & $\begin{array}{l}\geq 38 \\
\text { weeks }\end{array}$ \\
\hline Class I & - & - & $13(100 \%)$ \\
\hline Class II & - & $1(5 \%)$ & $19(95 \%)$ \\
\hline Class III & $2(20 \%)$ & $3(30 \%)$ & $5(50 \%)$ \\
\hline Class IV & $3(42.85 \%)$ & $3(42.85 \%)$ & - \\
\hline
\end{tabular}

Table 7 represented that all patients (13) with grade I disease had delivery at term whereas patient with grade II had $95 \%$ term and 5\% preterm delivery. Mothers with grade III disease had $50 \%$ term delivery and $50 \%$ preterm delivery of which one had delivery at 28 weeks, another at delivery 32 week. For none of the patients with grade IV heart pregnancy continued till term. 2 patients went into labor at $<28$ wks. Premature termination was done for 4 patients, one at 29 weeks and for 3 between 34-35 wks. The baby of dead mother was delivered by postmortem cesarean section.

Table 8: Neonatal outcome.

\begin{tabular}{|c|c|c|c|c|c|c|c|c|}
\hline \multirow{2}{*}{$\begin{array}{l}\text { N.Y.H.A } \\
\text { grading }\end{array}$} & \multicolumn{4}{|c|}{ Birth weight (kg) } & \multirow{2}{*}{$\begin{array}{l}\text { Apgar } \\
\text { score at } 1 \\
\text { minute }\end{array}$} & \multirow{2}{*}{$\begin{array}{l}\text { Apgar score } \\
\text { at } 5 \text { minutes }\end{array}$} & \multirow{2}{*}{$\begin{array}{l}\text { Admission } \\
\text { at NICU }\end{array}$} & \multirow{2}{*}{$\begin{array}{l}\text { Perinatal } \\
\text { mortality }\end{array}$} \\
\hline & $<1.5$ & $1.5-2$ & $>2-<2.5$ & $>=2.5$ & & & & \\
\hline $1(13$ cases $)$ & - & - & $\begin{array}{l}3 \\
(23.07 \%)\end{array}$ & $\begin{array}{l}10 \\
(76.92 \%)\end{array}$ & $\begin{array}{l}7-10 \text { for } \\
10,3-4 \text { for } \\
3\end{array}$ & $\begin{array}{l}7-10 \text { for } 11 \\
<3 \text { for } 2\end{array}$ & $2(15.38 \%)$ & $1(7.6 \%)$ \\
\hline $2(20$ cases $)$ & $1(5 \%)$ & $3(15 \%)$ & $2(10 \%)$ & $14(70 \%)$ & $\begin{array}{l}7-10 \text { for } \\
19,<3 \text { for } \\
1\end{array}$ & $\begin{array}{l}7-10 \text { for } 19 \\
<3 \text { for } 1\end{array}$ & $1(5 \%)$ & $1(5 \%)$ \\
\hline $3(10$ cases $)$ & $1(10 \%)$ & $2(20 \%)$ & $3(30 \%)$ & $4(40 \%)$ & $\begin{array}{l}7-10 \text { for } 6 \\
3-5 \text { for } 4\end{array}$ & $\begin{array}{l}7-10 \text { for } 5, \\
<3 \text { for } 5\end{array}$ & $5(50 \%)$ & $1(10 \%)$ \\
\hline 4(7 cases $)$ & $\begin{array}{l}3 \\
(42.85 \%)\end{array}$ & $\begin{array}{l}1 \\
(14.28 \%)\end{array}$ & $\begin{array}{l}2 \\
(28.57 \%)\end{array}$ & - & $\begin{array}{l}7-10 \text { for } 4, \\
<3 \text { for } 2\end{array}$ & $\begin{array}{l}7-10 \text { for } 4 \\
<3 \text { for } 2\end{array}$ & $6(85.71 \%)$ & $2(28.57 \%)$ \\
\hline
\end{tabular}

Table 8 described neonatal outcome. $23.07 \%$ babies of grade I, $30 \%$ babies of grade II, $60 \%$ babies of grade III and $100 \%$ babies of grade IV mothers were of low birth weight (LBW) weighing $<2.5 \mathrm{~kg}$. Extreme LBW weighing $<1.5 \mathrm{~kg}$ were seen in $5 \%$ patients of grade II, $10 \%$ of mothers of grade III and $42.85 \%$ of mothers with grade IV heart disease. $15.38 \%$ babies of grade I, $5 \%$ babies of grade II, $50 \%$ of grade III and $85.71 \%$ of grade IV heart disease mothers had to be admitted at SNCU (Sick Neonatal Care Unit) due extreme prematurity and LBW and poor Apgar score. 2 of grade IV and one each of grade III, II and I. were died.

Baby of mother with grade I heart disease died due to neonatal septicemia. Two babies of grade IV mother died of multiorgan failure in extremely premature and LBW baby. One baby of mother with grade III disease died of gross birth asphyxia (Apgar score at 5 min was 2). The baby of mother grade II heart disease died due to extreme prematurity and LBW.

\section{DISCUSSION}

In the present study, we determined the type of cardiac lesion and assessed the feto-maternal outcomes in pregnant women with cardiac disease. Cardiac disease continues to be a risk factor for maternal and neonatal mortality and morbidity. The incidence in our center was $2 \%$, probably due to escape of diagnosis because of trivial or asymptomatic nature of the disease. Incidence is bit higher at our neighboring country Pakistan. ${ }^{6}$ In South Africa $0.65 \%$ of all pregnant women have heart disease. ${ }^{7}$ In UK the incidence of heart disease during pregnancy has remained constant at $0.9 \%$ over several decades. ${ }^{8}$ Most of them were primigravidas (54\%) and were in their mid-twenties (84\%). RHD was most common etiology of heart disease in this study (74\%), MS being most 
common (20\%), which is supported by other studies. ${ }^{9,10}$ Congenital heart disease accounted for $26 \%$ of cases, among which ASD was most common (16\%). In this study LBW babies and fetal mortality were more among patients with heart disease was also reflected in other studies. ${ }^{11-13}$ A total of $48 \%$ women were delivered vaginally in this study. The rate of low forceps was also high, $20 \%$. The high rate of forceps application was to prevent maternal exhaustion. The rate of caesarean section was $32 \%$. All unbooked patients had moderate to severe anemia on admission. One mother died due to congestive heart failure. The associated complications were $46 \%$ moderate to severe anemia, $60 \%$ patients had any of the following complications $12 \%$ Respiratory tract infection, $2 \%$ pregnancy induced hypertension (PIH) and $2 \%$ recurrence of rheumatic fever. Despite the potential for significant maternal mortality in most patients with cardiac disease, satisfactory outcome can be expected with careful antenatal, intrapartum and postpartum management.

\section{CONCLUSION}

Cardiac disease with pregnancy is one of the important causes of maternal death. Rheumatic heart disease is still the commonest cause of heart disease and mitral valve is the commonly affected area. Improvement of standard of living can reduce the incidence of rheumatic fever which in turn capable of lowering RHD. Maternal morbidity and mortality due to heart disease can be reduced appreciably by antenatal care, early diagnosis and management with the help of cardiologist and surgery in selected cases. Recent advancement in cardiology may result in more successful treatment of pregnant cardiac patients.

Funding: No funding sources Conflict of interest: None declared

Ethical approval: The study was approved by the Institutional Ethics Committee

\section{REFERENCES}

1. Klein LL, Galan HL. Cardiac disease in pregnancy. Obstet Gynecol Clin N Am. 2004;31(2):429-59.

2. Van Mook WNKA, Peeters L. Severe cardiac disease in pregnancy, part II: impact of congenital and acquired cardiac disease during pregnancy. Curr Opin Crit Care. 2005;11(5):435-48.

3. Anandaraja S, Kothari SS, Bahl VK. Management of valvular heart disease during pregnancy. Ind Heart J. 2005;A57(2):101-8.

4. Saving Mothers. A report of the National Committee on Confidential Enquiries into maternal deaths in South Africa (1999-2001) DOH. Pretoria: 162-74.

5. Nqayana T, Moodley J, Naidoo DP. Cardiac disease in pregnancy. Cardiovasc J Afr. 2008;19(3):145-51.

6. Asghar F, Kokab H. Evaluation and Outcome of Pregnancy Complicated by Heart Disease. J Pak Med Assoc. 2005;55(10):416-9.

7. Naidoo DP1, Desai DK, Moodley J. Maternal deaths due to pre-existing cardiac disease. Cardiovasc J S Afr. 2002;13(1):17-20.

8. Steer PJ. Pregnancy and contraception In: Gatzoulis MA, Swan L,Therrien J, Pantely GA, editors. Adult Congenital Heart Disease: Practical Guide. Oxford: BMJ/Blackwell Publishing; 2005. p. 16-35.

9. Bhatla N, Lal S, Behera G, Kriplani A, Mittal S, Agarwal N, et al. Cardiac disease in pregnancy. Int $\mathbf{J}$ Gynaecol Obstet. 2003;82(2):153-9.

10. Doshi HU Oza HV, Tekani H, Modi K. Cardiac disease in pregnancy-maternal and perinatal outcome. JIMA. 2010;5:108(5):278-80.

11. Leary PJ, Leary SES, Stout KK, Schwartz SM, Esterling TS, Maternal, Perinatal, and Postneonatal Outcomes in Women with Chronic Heart Disease in Washington State. Obstet Gynecol. 2012;120(6): 1283-90.

12. Siu SC, Sermer M, Colman JM, Alvarez AN, Mercier LA, Morton BC, et al. Prospective multicenter study of pregnancy outcomes in women with heart disease. Circulation. 2001;104(5):515-21.

13. Siu SC, Sermer M, Harrison DA, Grigoriadis E, Liu $\mathrm{G}$, Sorensen S, et al. Risk and predictors for pregnancy-related complications in women with heart disease. Circulation. 1997;96(9):2789-94.

Cite this article as: Shah PT, Bhagat MA, Patel RV Yadav SM. Cardiac diseases in pregnancy and its feto-maternal outcome. Int J Reprod Contracept Obstet Gynecol 2018;7:4747-51. 